\title{
ANALISIS PERILAKU LALU LINTAS PENGGUNA JALAN DI SEKITAR SIMPANG GENDENGAN
}

\section{Traffic Behavior Analysis of Road Users around the Gendengan Intersection}

\author{
Nurul Hidayati \\ Program Studi S2 Teknik Sipil, Fakultas Teknik \\ Universitas Muhammadiyah Surakarta \\ J1. A. Yani, Mendungan, Pabelan, Kartasura \\ Sukoharjo, Jawa Tengah \\ nurul.hidayati@ums.ac.id
}

\author{
Agung Erwanda \\ Program Studi S2 Teknik Sipil, Fakultas Teknik \\ Universitas Muhammadiyah Surakarta \\ Jl. A. Yani, Mendungan, Pabelan, Kartasura \\ Sukoharjo, Jawa Tengah \\ erwandaagung@gmail.com
}

\begin{abstract}
This study focused on the behavior of road users (biker/rider), especially around the Gendengan Intersection in Surakarta. This study aims to determine the types of violations, the causes, and effects that occur around the intersection. The primary data used are observation data of violations and questionnaires of 400 respondents. This study also uses data on traffic accidents and violations from the SATLANTAS of Surakarta Police and the IRSMS of KORLANTAS POLRI. The analysis refers to Law No.22 of 2009. Based on the Police data analysis, there are $87.98 \%$ of violations in Surakarta related to driver behavior, while using the primary data, it was found around $48.32 \%$. Lack of awareness of orderly traffic causes the driver to ignore his safety. This can be seen from the percentage of respondents who answered YES greater than NO happening in almost all violation types. Traffic violations can be a major factor in traffic accidents. Therefore, the implementation of strict rules needs to be done for those who violate, either in the form of fines or imprisonment.
\end{abstract}

Keywords: behavior, violation, accident, traffic.

\begin{abstract}
Abstrak
Penelitian ini difokuskan pada perilaku berlalu lintas pengendara di jalan, khususnya di sekitar Simpang Gendengan Surakarta. Penelitian ini bertujuan untuk mengetahui tipe-tipe pelanggaran, penyebab dan dampak pelanggaran yang terjadi di sekitar simpang tersebut. Data primer yang digunakan adalah data pengamatan lapangan dan kuesioner dari 400 responden. Penelitian ini juga menggunakan data kecelakaan dan pelanggaran lalu lintas dari Satlantas Polresta Surakarta dan IRSMS KORLANTAS POLRI. Analisis mengacu pada Undang-Undang No.22 Tahun 2009. Berdasarkan hasil analisis data Kepolisian diperoleh 87,98\% tipe pelanggaran di Surakarta berkaitan dengan perilaku pengemudi, sedangkan dari data primer diperoleh sebesar 48,32\%. Kurangnya kesadaran akan tertib berlalu lintas menyebabkan pengemudi pengabaikan keselamatannya. Hal ini terlihat dari prosentase responden yang menjawab Ya lebih besar dari Tidak terjadi hampir pada semua tipe pelanggaran. Pelanggaran lalu lintas dapat menjadi faktor utama kecelakaan lalu lintas. Oleh karena itu, penerapan aturan yang ketat perlu dilakukan bagi yang melanggar, baik berupa hukuman denda atau penjara.
\end{abstract}

Kata kunci: perilaku, pelanggaran, kecelakaan, lalu lintas

\section{PENDAHULUAN}

Kecelakaan lalu lintas (lakalantas) menurut Undang-undang No. 22 tahun 2009 dinyatakan sebagai suatu peristiwa di jalan yang melibatkan kendaraan dengan atau tanpa pengguna lain yang menimbulkan korban termasuk kerugian harta benda. Lakalantas dapat dapat terjadi karena beberapa faktor, yaitu manusia, kendaraan, jalan dan lingkungan (Mohanty \& Gupta, 2015 dan Javadi dkk, 2015). Meskipun demikian, lakalantas sering disebabkan oleh kombinasi sejumlah faktor tersebut di atas (termasuk kondisi cuaca). Sebagai salah 
satu faktor penyebab, manusia sebagai pengguna dapat dibedakan menjadi pejalan kaki, pengendara/pengemudi, penumpang maupun pengguna jalan lainnya. Berdasarkan pengamatan, sering terlihat pengguna jalan mengabaikan keselamatan berkendara. Kondisi ini diantaranya terlihat dari masih adanya pengendara yang menerobos lampu merah di simpang, mengoperasikan hand phone, dan tidak menggunakan helm pengaman. Tidak taatnya pengendara tersebut bisa disebabkan karena ketidaktahuan akan peraturanperaturan lalu lintas yang ada dan berlaku di suatu area tertentu. Meskipun demikian, dimungkinkan juga sebenarnya pengendara tahu dan paham akan peraturan tersebut, tetapi karena sudah menjadi kebiasaan sehingga cenderung kurang aware terhadap pelaksanaannya.

Pelanggaran terhadap aturan berlalu lintas dapat menjadi awal terjadinya kecelakaan lalu lintas. Oleh karena itu untuk mengurangi kecelakaan maka perlu mengurangi atau menghilangkan pelanggaran tersebut. Hal ini seperti yang disampaikan oleh pihak Korlantas Polri dalam Aszhari (2018). Pelanggaran terhadap aturan lalu lintas banyak didominasi oleh pengendara sepeda motor (Adriannoor, 2017). Hal ini juga dibuktikan dengan tingginya tingkat keterlibatan sepeda motor dalam kejadian lakalantas. Berdasarkan data Perhubungan Darat dalam Angka 2010 dalam Hidayati (2013), sekitar 60,63\% kecelakaan lalu lintas di Indonesia melibatkan pengendara motor, diikuti mobil sebanyak 29,85\%. Meskipun demikian, jika prosentase tersebut dibandingkan dengan jumlah kendaraan yang tercatat di Kepolisian, maka mobil akan menjadi lebih berbahaya dibandingkan sepeda motor. Kelengkapan berkendara (kondisi laik jalan baik administrasi maupun operasional) menjadi salah satu faktor yang mempengaruhi perilaku sipengendara. Sebagai contoh: seorang pengendara motor tanpa helm akan gelisah ketika terlihat di depannya ada operasi lalu lintas di jalan. Agar tidak terkena tilang, kadang terlihat pengendara berputar balik tiba-tiba atau berlalu dengan kencang agar tidak diberhentikan oleh petugas. Ketidaklengkapan tersebut justru dapat membahayakan diri pengemudi kendaraan dan bahkan membahayakan pengguna jalan lainnya termasuk pejalan kaki. Contoh lain adalah pengendara yang tidak memiliki atau lupa membawa Surat Ijin Mengemudi (SIM), ataupun Surat Tanda Nomor Kendaraan (STNK). Pelanggaran aturan lalu lintas dapat terjadi di ruas jalan maupun di persimpangan, termasuk yang terjadi di Kota Surakarta, salah satunya di sekitar Simpang Gendengan.

Simpang Gendengan merupakan persilangan/pertemuan antara ruas jalan Jl. Slamet Riyadi dengan Jl. Dr. Wahidin dan Jl. Dr Moewardi yang diatur dengan menggunakan lampu lalu lintas. Simpang ini merupakan salah satu simpang utama di Kota Solo, dengan tipe aktifitas di sekitarnya adalah perkantoran, rumah sakit, perbelanjaan sekolah, dan fasilitas umum lainnya. Selain itu, simpang ini juga berada tidak jauh dari Stasiun Purwosari, Stadion Sriwedari dan Stadiun Manahan. Guna mendukung terjadinya pergerakan lalu lintas yang aman, biasanya suatu simpang bersinyal dilengkapi dengan perlengkapan jalan lainnya, yaitu rambu lalu lintas dan marka jalan. Beberapa pelanggaran lalu lintas yang telah disebutkan di alenia pertama juga terjadi di sekitar lokasi ini. Seberapa banyak pelanggaran yang terjadi di lapangan perlu diidentifikasi jenis dan penyebabnya. Hal ini dilakukan agar dapat dipikirkan solusi yang tepat guna mendukung terwujudnya Surakarta sebagai salah satu kota yang tertib berlalu lintas.

Berdasarkan latar belakang di atas, penelitian ini perlu dilakukan untuk mengidentifikasi tipe pelanggaran lalu lintas yang ada di lokasi tersebut, kemudian mengetahui penyebab, serta dampaknya. Penelitian ini menggunakan data primer berupa hasil kuisioner dan pengamatan kondisi lalu lintas di lapangan serta menggunakan data sekunder dari Dinas 
Kepolisian sejak tahun 2012-2016. Meskipun penelitian tentang perilaku lalu lintas pernah dilakukan peneliti lain, tetapi penelitian di sekitar Simpang Gendengan ini didasarkan pada data primer sesuai kondisi realitas lalu lintas di lokasi tersebut.

\section{METODE PENELITIAN}

Penelitian ini berada di sekitar Simpang Gendengan di antara Jl. Brigjen Slamet Riyadi, Jl. Dr.Wahidin, dan J1. Dr. Moewardi Surakarta. Data primer yang digunakan dalam analisis mencakup data pelanggaran lalu lintas, kuisioner, geometrik dan lingkungan. Selain itu, analisis ini juga menggunakan data pelanggaran, dan data lakalantas yang bersumber dari Polresta Surakarta.

Survei primer dilakukan pada tanggal 14 Agustus 2017 selama 6 jam (pukul 06.00 - 12.00) diambil di tiap ruas jalan di simpang tersebut. Data geometrik jalan dan lingkungan yang diperlukan adalah lebar jalan, jumlah lajur lalu lintas, lebar bahu jalan, lebar median, lebar trotoar, dan kondisi kelengkapan jalan (termasuk rambu dan marka). Survai investigasi pelanggaran lalu lintas dilakukan untuk mengamati pelanggaran yang terjadi di lapangan pada waktu survai beserta jenisnya serta dengan melakukan wawancara. Wawancara dilakukan dengan memberikan pertanyaan-pertanyaan yang tersusun dalam suatu form kuisioner.

Suatu penelitian yang menggunakan data pengamatan perlu melakukan validasi data atau validitas guna membuktikan apakah hasil yang diamati sesuai dengan kenyataan atau tidak. Validitas dapat dilakukan dengan teknik triangulasi, yaitu teknik pemeriksaan kevalidan dengan memanfaatkan sesuatu yang lain dari data itu sendiri sebagai pembanding (Moleong, 2006). Proses tersebut dapat dilakukan dengan cara membandingkan hasil observasi dengan kuesioner, atau literatur, atau dengan dokumen yang berkaitan lainnya.

\section{HASIL DAN PEMBAHASAN}

\section{Identifikasi Tipe-Tipe Pelanggaran}

Pelanggaran lalu lintas di jalan raya dapat diklasifikasikan dalam beberapa kelompok/tipe. Satlantas Polresta Surakarta mengklasifikasikannya menjadi 2 kelompok berdasarkan faktor utamanya, yaitu perilaku dan kendaraan. Hal ini dapat dilihat pada Tabel 1 .

Tabel 1. Jumlah pelanggaran lalu lintas di Surakarta

\begin{tabular}{|c|c|c|c|c|c|c|c|c|}
\hline \multirow{3}{*}{ Tahun } & \multirow{3}{*}{$\mathbf{P}$} & \multicolumn{7}{|c|}{ Jumlah Pelanggaran } \\
\hline & & \multicolumn{4}{|c|}{ Faktor Perilaku } & \multicolumn{3}{|c|}{ Faktor Kendaraan } \\
\hline & & $\mathbf{K B}$ & $\mathbf{S}$ & $\mathbf{R}$ & $\mathbf{K}$ & KK & $\mathbf{L}$ & $\mathbf{P}$ \\
\hline 2012 & 37.305 & 7.571 & 3.847 & 22.178 & 0 & 2.182 & 1.238 & 289 \\
\hline 2013 & 38.270 & 2.601 & 5.181 & 26.145 & 90 & 944 & 2.679 & 630 \\
\hline 2014 & 39.175 & 5.486 & 7.489 & 19.536 & 0 & 1.611 & 4.701 & 352 \\
\hline 2015 & 39.655 & 1.090 & 6.351 & 27.351 & 56 & 712 & 3.975 & 120 \\
\hline 2016 & 45.510 & 9.091 & 406 & 31.419 & 3 & 3.528 & 498 & 565 \\
\hline \multirow{2}{*}{ Jumlah } & \multirow{2}{*}{199.915} & 25.839 & 23.274 & 126.629 & 149 & 8.977 & 13.091 & 1.956 \\
\hline & & \multicolumn{4}{|c|}{$175.891(87,98 \%)$} & \multicolumn{3}{|c|}{$24.024(12,02 \%)$} \\
\hline
\end{tabular}

Keterangan: P (Pelanggar), K (Kecepatan), KB (Kelengkapan berkendara), KK (Komponen kendaraan), S (Surat SIM dan STNK), L (Lampu), R (Rambu dan marka), P (Plat nomor) 
Berdasarkan pengamatan dapat diidentifikasi bagaimanakah perilaku pengendara kendaraan bermotor di jalan. Identifikasi ini dilakukan terhadap tipe pelanggaran lalu lintas yang dikelompokan menjadi 3 unsur, yaitu perilaku pengendara (manusia), kendaraan, dan kelengkapan jalan. Jumlah pelanggaran tiap kelompok di atas dapat dilihat pada Tabel 2, sedangkan rincian tipe pelanggaran ditampilkan pada Tabel 3 sampai Tabel 5.

Tabel 2. Jumlah pelanggaran di lokasi penelitian tiap faktor

\begin{tabular}{ccccc}
\hline \multirow{2}{*}{ No } & \multirow{2}{*}{ Kelompok } & \multicolumn{2}{c}{ Pelanggaran } \\
\cline { 3 - 5 } & & Jumlah & \% \\
\hline 1 & Perilaku & & 3.222 & 48,32 \\
\hline 2 & Kendaraan & & 1.001 & 15,01 \\
\hline 3 & Kelengkapan jalan & & 2.445 & 36,67 \\
\hline & & Jumlah & 6.668 & 100,00 \\
\hline
\end{tabular}

Tabel 3. Jumlah pelanggaran terkait perilaku pengendara/pengemudi

\begin{tabular}{clcc}
\hline \multirow{2}{*}{ No } & & Jenis & Pelanggaran \\
\cline { 3 - 4 } & & Jumlah & \% \\
\hline 1 & Parkir pada area larangan & 3 & 0,09 \\
\hline 2 & Bergerak ke samping tanpa isyarat & 1.573 & 48,82 \\
\hline 3 & Berbalik arah tanpa isyarat & 1.086 & 33,71 \\
\hline 4 & Menggunakan HP & 413 & 12,82 \\
\hline 5 & Mengendarai sepeda motor dengan penumpang lebih dari satu & 51 & 1,58 \\
\hline 6 & Pengemudi/penumpang tidak menggunakan sabuk pengaman & 45 & 1,4 \\
\hline 7 & Menaikkan dan/atau menurunkan penumpang sembarangan & 2 & 0,06 \\
\hline 8 & $\begin{array}{l}\text { Pengendara angkutan umum tidak menggunakan lajur yang } \\
\text { telah ditentukan }\end{array}$ & 3 & 0,09 \\
\hline 9 & Berpegangan pada kendaraan lain untuk ditarik & 1 & 0,03 \\
\hline 10 & Tidak mengenakan helm & 45 & 1,4 \\
\hline
\end{tabular}

Tabel 4. Jumlah pelanggaran terkait unsur kendaraan

\begin{tabular}{clcc}
\hline \multirow{2}{*}{ No } & Jenis & \multicolumn{2}{c}{ Pelanggaran } \\
\cline { 3 - 4 } 1 & Tidak menyalakan lampu motor di siang hari & Jumlah & \% \\
\hline 2 & Tidak ada Plat Nomor & 16 & 1,6 \\
\hline 3 & $\begin{array}{l}\text { Melanggar aturan tata cara penggandengan dan penempelan } \\
\text { dengan kendaraan lain }\end{array}$ & 5 & 0,5 \\
\hline & $\begin{array}{l}\text { Tidak memasang segitiga pengaman, lampu isyarat peringatan } \\
\text { bahaya, atau isyarat lalu lintas pada saat berhenti atau parkir } \\
\text { dalam keadaan darurat }\end{array}$ & 1 & 0,1 \\
\hline 5 & Memodifikasi/merubah bodi kendaraan & 2 & 0,2 \\
\hline
\end{tabular}


Tabel 5. Jumlah pelanggaran terkait unsur kelengkapan jalan

\begin{tabular}{clccc}
\hline \multirow{2}{*}{ No } & \multirow{2}{*}{ Jenis } & \multicolumn{2}{c}{ Pelanggaran } \\
\cline { 3 - 4 } & & Jumlah & $\%$ \\
\hline 1 & Melanggar lampu lalu lintas & 790 & 32,31 \\
\hline 2 & Melanggar marka membujur & 207 & 16,65 \\
\hline 3 & Melanggar marka lambang sepeda & 388 & 8,43 \\
\hline 4 & Melanggar marka yellow box juction & 8 & 15,87 \\
\hline 5 & Melanggar rambu larangan belok kanan & 579 & 0,33 \\
\hline 6 & Melanggar lajur belok kiri langsung & 67 & 23,68 \\
\hline 7 & Melanggar lajur contra flow & 2.445 & 100,00 \\
\hline \multirow{2}{*}{ Total } & & \\
\hline
\end{tabular}

Tabel 3 sampai Tabel 5 menunjukkan bahwa pelanggaran yang paling banyak tiap kelompok adalah: berpindah lajur tanpa memberi isyarat sejumlah 1.573 , lampu utama tidak dinyalakan di siang hari sejumlah 977, dan melanggar lampu merah sejumlah 790 .

\section{Penyebab Pelanggaran Aturan Berlalu Lintas}

Pelanggaran aturan berlalu lintas dapat dipengaruhi oleh kurangnya pengetahuan pengguna jalan akan undang-undang/peraturan terkait atau karena faktor perilaku masing-masing. Oleh karena itu, penelitian ini menggunakan media kuesioner kepada pengemudi motor dan mobil untuk mengetahui perilaku mereka dalam berlalu lintas. Jumlah responden yang diambil adalah 400 orang untuk mewakili populasi Kota Surakarta yang berpenduduk kurang lebih 515.549 orang. Berdasarkan rekapitulasi kuesioner dapat diketahui distribusi responden berdasarkan kelompok umur seperti terlihat pada Grafik 1.

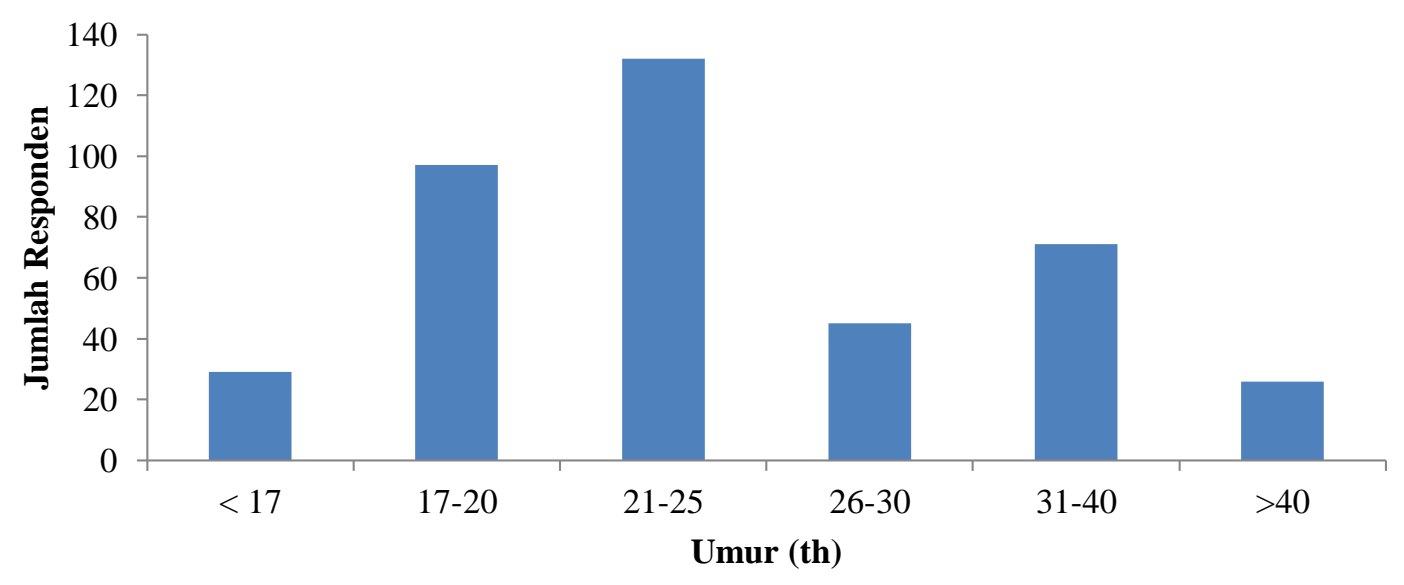

Gambar 1. Karakteristik responden berdasarkan umur

Karakteristik responden didasarkan pada pengetahuan akan kelengkapan jalan dapat dilihat pada Tabel 6. Selain itu dapat dilihat distribusi responden berdasarkan tipe pelanggaran yang pernah dilakukan seperti terlihat pada Tabel 7. 
Tabel 6. Karakteristik responden berdasarkan pengetahuan akan kelengkapan jalan

\begin{tabular}{|c|c|c|c|c|}
\hline No & Kelengkapan Jalan & Pengetahuan & Jumlah & $\%$ \\
\hline \multirow{2}{*}{1} & \multirow{2}{*}{ Marka umum jalan } & Ya & 293 & 73,25 \\
\hline & & Tidak & 107 & 26,75 \\
\hline \multirow{2}{*}{2} & \multirow{2}{*}{ Rambu lalu lintas } & $\mathrm{Ya}$ & 396 & 99 \\
\hline & & Tidak & 4 & 1 \\
\hline \multirow{2}{*}{3} & \multirow{2}{*}{$\begin{array}{l}\text { Marka khusus simpang (Yellow box } \\
\text { juction) }\end{array}$} & $\mathrm{Ya}$ & 167 & 41,75 \\
\hline & & Tidak & 233 & 58,25 \\
\hline \multirow{2}{*}{4} & \multirow{2}{*}{ Lampu lalu lintas } & Ya & 396 & 99 \\
\hline & & Tidak & 4 & 1 \\
\hline \multirow{2}{*}{5} & \multirow{2}{*}{ Zebra cross } & $\mathrm{Ya}$ & 391 & 97,75 \\
\hline & & Tidak & 9 & 2,25 \\
\hline
\end{tabular}

Berdasarkan Tabel 6 dapat diketahui, mayoritas responden tahu tentang perlengkapan penunjang keselamatan lalu lintas kecuali yellow box junction. Hal ini terlihat dari prosentase yang menjawab Ya lebih besar dari Tidak. Meskipun demikian, pada Tabel 7 terlihat prosentase yang pernah berpengalaman menerobos lampu merah jauh lebih besar dari yang belum pernah. Selain itu, Tabel 7 juga memperlihatkan hanya tipe pelanggaran tidak membawa STNK saja yang prosentase pelanggarnya lebih sedikit. Kondisi tersebut menunjukkan bahwa ada kecenderungan dari pengendara untuk mengabaikan aturan berlalu lintas dan mengabaikan keselamatan berlalu lintas.

Tabel 7. Karakteristik responden berdasarkan tipe pelanggaran

\begin{tabular}{|c|c|c|c|c|}
\hline No & Tipe Pelanggaran & Pengalaman & Jumlah & $\%$ \\
\hline \multirow{2}{*}{1} & \multirow{2}{*}{ Menerobos lampu merah } & Ya & 268 & 67,0 \\
\hline & & Tidak & 132 & 33,0 \\
\hline \multirow{2}{*}{2} & \multirow{2}{*}{ Tidak membawa STNK } & Ya & 188 & 47,0 \\
\hline & & Tidak & 212 & 53,0 \\
\hline \multirow{2}{*}{3} & \multirow{2}{*}{ Tidak membawa SIM } & $\mathrm{Ya}$ & 227 & 56,8 \\
\hline & & Tidak & 173 & 43,3 \\
\hline \multirow{2}{*}{4} & \multirow{2}{*}{$\begin{array}{l}\text { Berbelok tidak memberi isyarat (lampu } \\
\text { sein) }\end{array}$} & $\mathrm{Ya}$ & 245 & 61,3 \\
\hline & & Tidak & 155 & 38,8 \\
\hline \multirow{2}{*}{5} & \multirow{2}{*}{ Mengebut di jalan } & Ya & 172 & 43,0 \\
\hline & & Tidak & 228 & 57,0 \\
\hline \multirow{2}{*}{6} & \multirow{2}{*}{$\begin{array}{l}\text { Pengendara mobil berhenti tanpa memberi } \\
\text { isyarat }\end{array}$} & Ya & 115 & 60,2 \\
\hline & & Tidak & 76 & 39,8 \\
\hline \multirow{2}{*}{7} & \multirow{2}{*}{$\begin{array}{l}\text { Pengendara mobil tanpa menggunakan } \\
\text { sabuk pengaman }\end{array}$} & $\mathrm{Ya}$ & 121 & 63,4 \\
\hline & & Tidak & 70 & 36,6 \\
\hline
\end{tabular}




\begin{tabular}{ccccc}
\hline No & \multicolumn{1}{c}{ Tipe Pelanggaran } & Pengalaman & Jumlah & \% \\
\hline \multirow{2}{*}{8} & Pengendara motor tanpa helm (SNI) & Ya & 128 & $\mathbf{6 1 , 2}$ \\
\cline { 3 - 5 } & & Tidak & 81 & 38,8 \\
\hline \multirow{2}{*}{9} & $\begin{array}{l}\text { Pengendara motor memboncengkan } \\
\text { penumpang lebih dari 1 Orang }\end{array}$ & Ya & 169 & $\mathbf{8 0 , 9}$ \\
\cline { 3 - 5 } 10 & $\begin{array}{l}\text { Pengendara motor tidak menyalakan } \\
\text { lampu di siang hari }\end{array}$ & Tidak & 40 & 19,1 \\
\cline { 3 - 5 } & & Ya & 169 & $\mathbf{8 0 , 9}$ \\
\hline
\end{tabular}

\section{Dampak Pelanggaran Lalu Lintas}

Berdasarkan hasil survai yang telah disampaikan di atas, dapat dikatakan bahwa mayoritas penyebab pelanggaran lalu lintas adalah faktor perilaku masyarakat. Kondisi ini juga sesuai dengan data sekunder yang ada di Tabel 1, yaitu 87,98\% pelanggaran yang tercatat di Kepolisian adalah terkait perilaku. Kondisi ini tidak hanya di Surakarta saja, berdasarkan data dari Korlantas Polri, jenis pelanggaran yang sering dilakukan masyarakat seperti terlihat di Gambar 2 adalah tidak memiliki/membawa SIM, melanggar batas kecepatan, dan mengemudi dengan tidak wajar. Sebagaimana diketahui bahwa, pelanggaran lalu lintas dapat menyebabkan lakalantas. Oleh karena itu, perlu usaha yang lebih intensif lagi untuk melakukan sosialisasi keselamatan berlalu lintas. Hal ini dilakukan agar dapat menekan atau mengurangi jumlah kejadian lakalantas. Berdasarkan data dari Kepolisian dapat diketahui jumlah kejadian kecelakaan di Kota Surakarta tahun 2012-2016 seperti terlihat pada Tabel 8.

Tabel 8. Jumlah kecelakaan lalu lintas di Kota Surakarta (Satlantas Polresta Surakarta)

\begin{tabular}{cccccc}
\hline \multirow{2}{*}{ Tahun } & \multirow{2}{*}{$\begin{array}{c}\text { Jumlah } \\
\text { Kasus }\end{array}$} & MD & LB & LR & $\begin{array}{c}\text { Kerugian Materiil } \\
(\text { Rp) }\end{array}$ \\
\cline { 3 - 5 } 2012 & 583 & 67 & 1 & 599 & 349.050 .000 \\
\hline 2013 & 533 & 69 & 2 & 544 & 356.250 .000 \\
\hline 2014 & 503 & 68 & 4 & 505 & 412.300 .000 \\
\hline 2015 & 558 & 61 & 4 & 572 & 354.400 .000 \\
\hline 2016 & 681 & 59 & 2 & 692 & 336.500 .000 \\
\hline Jumlah & 2.858 & 324 & 13 & 2.912 & 1.808 .500 .000 \\
\hline
\end{tabular}

Keterangan: MD (meninggal dunia), LB (luka berat), LR (luka ringan)

Tabel 8 menunjukkan bahwa jumlah kecelakaan di Kota Surakarta selama 3 tahun (2014 2016) mengalami peningkatan. Meskipun demikian, kerugian materiil selama kurun waktu tersebut mengalami penurunan. Hal ini disebabkan ada penurunan jumlah korban meninggal dan luka berat. 


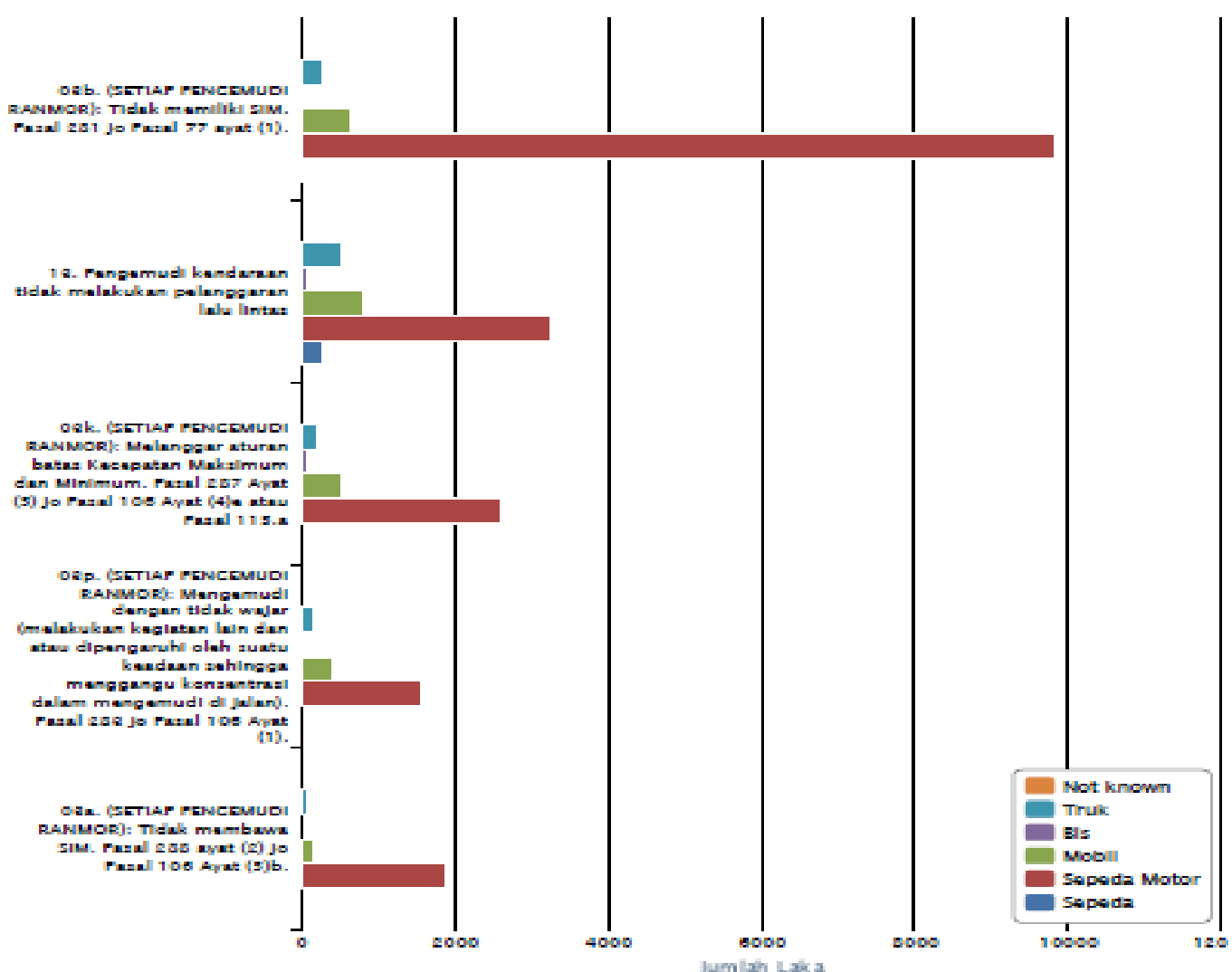

Gambar 2. Tipe pelanggaran yang mengakibatkan lakalantas

(http://www.korlantas-irsms.info/graph/violationTypeData)

Sebagaimana telah disampaikan sebelumnya, pelanggaran lalu lintas yang dilakukan oleh pengemudi dapat menjadi faktor utama terjadinya lakalantas. Oleh karena itu aturan terkait tindakan yang harus dilakukan pada pengemudi perlu diterapkan di lapangan. Hal tersebut diharapkan dapat memberi efek jera pada masyarakat yang melanggarnya.

\section{Tindak Pidana Berdasarkan Tipe Pelanggaran Lalu Lintas}

Tipe pelanggaran lalu lintas yang terjadi di Simpang Gendengan telah disampaikan dalam Tabel 2 sampai Tabel 5. Tindakan apa yang perlu dilakukan terhadap pelanggar diatur dalam Undang-undang No. 22 tahun 2009 terkait dengan Lalu Lintas dan Angkutan Jalan.

Jumlah pelanggaran yang terjadi di lokasi penelitian (lihat Tabel 2) adalah 6.668 dengan 3.222 diantaranya terkait dengan perilaku penguna (manusia). Berdasarkan Tabel 3 dapat diketahui tipe pelanggaran yang berkaitan dengan perilaku tersebut. Data tersebut kemudian dihubungkan dengan tindakan yang dapat dikenakan pada pelaku dan tercantum dalam UU di atas, diantaranya adalah sebagai berikut:

1. Pelanggaran terkait parkir tidak pada tempatnya adalah sanksi pidana kurungan paling lama 2 bulan atau denda paling banyak Rp. 500.000,00, seperti tercantum dalam Pasal 298.

2. Sanksi bagi pelanggaran terkait pengendara yang tidak memberikan isyarat ketika berbelok adalah kurungan paling lama 1 bulan atau denda paling banyak Rp. $250.000,00$. 
3. Pasal 283 menyatakan bahwa pengemudi yang menganggu orang lain dapat dikenai kurungan paling lama 3 bulan atau denda paling banyak Rp. 750.000,00.

4. Pasal 292 menyatakan pengendara motor yang mengangkut penumpang lebih dari 1 orang dapat dikenai denda paling banyak Rp 250.000,00.

5. Pasal 289 menyatakan pengemudi dan penumpang yang tidak mengenakan sabuk keselamatan dapat dikenai denda paling banyak Rp. 250.000,00.

Berdasarkan Tabel 2 dapat diketahui selain perilaku, pelanggaran lalu lintas juga berkaitan dengan kondisi kendaraan yang digunakan pengemudi serta terkait unsur kelengkapan jalan. Diantara 6.668 pelanggaran yang terjadi di sekitar Simpang Gendangan, 1.001 $(15,01 \%)$ berkaitan dengan kendaraan, sedangkan $2.445(36,67 \%)$ terkait kelengkapan. Sebagaimana perilaku, tipe pelanggaran yang terjadi tersebut kemudian juga dihubungkan dengan tindakan yang dapat dikenakan pada pelaku, yaitu sebagai berikut:

1. Pelanggaran tidak menyalakan lampu utama di siang hari mencapai 977 (97,6\%). Tipe pelanggaran ini dapat dikenai denda paling banyak Rp. 100.000,00.

2. Ada sekitar $1,6 \%$ responden yang melakukan pelanggaran tanpa plat nomor kendaraan. Meskipun sangat kecil, dalam Pasal 285 UU di atas dinyatakan bahwa setiap pengendara motor yang tidak memenuhi persyaratan teknis dan laik jalan dapat dikenai denda paling banyak Rp. 250.000,00.

3. Responden yang menerobos lampu merah mencapai 32,31\%, melanggar marka 40,94\%, menggunakan lajur tidak semestinya $26,42 \%$ dan sisanya melanggar rambu. Berdasarkan Pasal 287, pelanggaran jenis ini dapat dikenai denda paling banyak Rp. $500.000,00$.

\section{KESIMPULAN}

Berdasarkan hasil analisis dapat disimpulkan bahwa:

1. $87,98 \%$ tipe pelanggaran di Surakarta berkaitan dengan perilaku pengemudi. Hal ini juga terjadi di Simpang Gendengan yang mayoritas pelanggaran terkait perilaku yaitu sebesar $48,32 \%$.

2. Kurangnya kesadaran akan tertib berlalu lintas menyebabkan pengemudi pengabaikan keselamatan berlalu lintas. Hal ini terlihat dari prosentase responden yang menjawab Ya lebih besar dari Tidak hampir pada semua tipe pelanggaran yang ditanyakan.

3. Pelanggaran lalu lintas dapat menjadi faktor utama kecelakaan lalu lintas. Hal ini dapat dilihat dari jumlah kecelakaan yang tinggi (sekitar 10.000 kejadian) disebabkan pengemudi motor tidak memiliki SIM. Oleh karena itu, penerapan aturan yang ketat perlu dilakukan bagi yang melanggar, baik berupa hukuman denda atau penjara.

Mengacu pada hasil penelitian ini, beberapa hal yang direkomendasikan untuk meningkatkan keselamatan berlalu lintas adalah:

1. Perlunya sosialisasi dampak pelanggaran lalu lintas yang lebih intensif kepada seluruh lapisan masyarakat melalui lembaga pendidikan maupun lembaga/instansi lainnya yang ada di masyarakat.

2. Perlu melibatkan seluruh komponen masyarakat dalam mensosialisasikan tertib berlalu lintas. 


\section{UCAPAN TERIMA KASIH}

Ucapan terima kasih disampaikan kepada Kepolisian Republik Indonesia melalui DIPA Korlantas Polri Tahun Anggaran 2018 yang telah memberikan Hibah Penelitian Traffic Accident Research Center (TARC) kepada penulis. Selain itu ucapan terima kasih juga disampaikan kepada Korlantas Polri beserta jajarannya, khususnya Satlantas Polresta Surakarta yang telah membantu dalam menyediakan data baik manual maupun online.

\section{DAFTAR PUSTAKA}

Adriannoor F. 2017. Pengendara Sepeda Motor Mendominasi Pelanggaran Lalu Lintas. https://www.antaranews.com/berita/663486/pengendara-sepeda-motor-mendominasipelanggaran-lalu-lintas

Anonim, 2009. Undang-Undang Republik Indonesia No. 22 Tahun 2009 Tentang Lalu Lintas dan Angkutan Jalan. Jakarta

Aszhari A. 2018. Tekan Angka Kecelakaan, Jangan Pernah Melanggar Lalu Lintas. https://www.liputan6.com/otomotif/read/3657076/tekan-angka-kecelakaan-janganpernah-melanggar-lalu-lintas.

DGoLT. 2011. Perhubungan Darat dalam Angka 2010 (Land Transportation in Figures 2010) VII. Jakarta: Directorate General of Land Transportation.

Hidayati, N. 2013. The Impact of the School Safety Zone on Passenger Car Equivalent Values in Indonesian Urban Roads. Ph.D. Thesis. Leeds, United Kingdom

Javadi SMH., Azad HF., Tahmasebi S., Rafiei H., Rahgozar M., Tajlili A. 2015. Study of Psycho-Social Factors Affecting Traffic Accidents Among Young Boys in Tehran. Iran Red Crescent Medical Journal. 17 (7).

Mohanty, Malaya dan Gupta, Ankit. 2015. Factors Afeecting Road Crash Modeling. Journal of Transport Literature, 9 (2), 15-19, April 2015. www.journal-of-transportliterature.org

Moleong, L.J, 2006. Metodologi Penelitian Kualitatif, PT. Remaja Rosdakarya, Bandung http://www.korlantas-irsms.info/graph/violationTypeData

Satlantas Polresta Surakarta. Data Kecelakaan dan Pelanggaran Lalu Lintas (unpublished). 